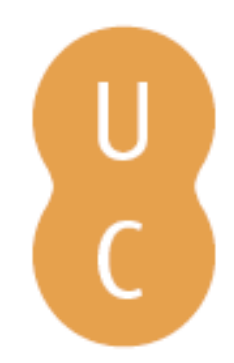

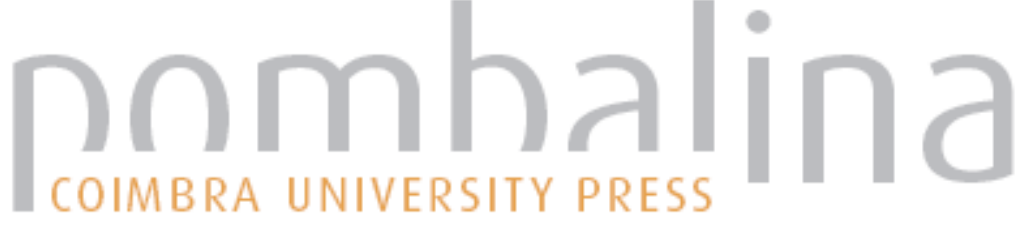

\section{La afición a Grecia de Pedro Henríquez Ureña y el nacimiento de Dioniso en México a comienzos del siglo XX}

\author{
Autor(es): $\quad$ Costa, Analía \\ Publicado por: Imprensa da Universidade de Coimbra \\ URL \\ persistente: URI:http://hdl.handle.net/10316.2/42960 \\ DOI: $\quad$ DOI:https://doi.org/10.14195/978-989-26-1439-7_17 \\ Accessed : $\quad$ 26-Apr-2023 09:45:36
}

A navegação consulta e descarregamento dos títulos inseridos nas Bibliotecas Digitais UC Digitalis, UC Pombalina e UC Impactum, pressupõem a aceitação plena e sem reservas dos Termos e Condições de Uso destas Bibliotecas Digitais, disponíveis em https://digitalis.uc.pt/pt-pt/termos.

Conforme exposto nos referidos Termos e Condições de Uso, o descarregamento de títulos de acesso restrito requer uma licença válida de autorização devendo o utilizador aceder ao(s) documento(s) a partir de um endereço de IP da instituição detentora da supramencionada licença.

Ao utilizador é apenas permitido o descarregamento para uso pessoal, pelo que o emprego do(s) título(s) descarregado(s) para outro fim, designadamente comercial, carece de autorização do respetivo autor ou editor da obra.

Na medida em que todas as obras da UC Digitalis se encontram protegidas pelo Código do Direito de Autor e Direitos Conexos e demais legislação aplicável, toda a cópia, parcial ou total, deste documento, nos casos em que é legalmente admitida, deverá conter ou fazer-se acompanhar por este aviso.

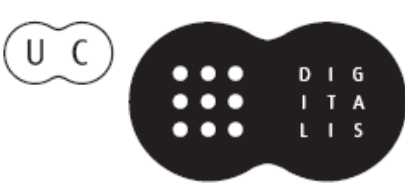




\section{Pervivencia del mundo clásico en la literatura:}

\section{tradición y relecturas}

\section{Aldo Rubén Pricco, Stella Maris Moro (coords.)}

IMPRENSA DA UNIVERSIDADE DE COIMBRA 


\title{
La afición a Grecia de Pedro Henríquez Ureña y el nacimiento de Dioniso en México a comienzos del siglo XX
}

\author{
(Pedro Henríquez Ureña's love for Greece and the birth of Dionysus in
} Mexico at the beginning of the 20th century)

\author{
Analía Costa (analiacostam@gmail.com) \\ Universidad Nacional de Rosario
}

\begin{abstract}
Resumen - Este trabajo indaga la puesta en escena del mito de Dioniso y la afición de Pedro Henríquez Ureña por la tradición clásica en México a comienzos del siglo XX.

Palabras Clave: Dioniso, tradición clásica, México, tragedia, paideia.
\end{abstract}

Авsтract - This work analyses the staging of the myth of Dionysus and the love of Pedro Henriquez Urena by the classical tradition in Mexico in the early twentieth century.

Keywords: Dionysus, classical tradition, Mexico, tragedy, paideia.

Ciudad de México, noche del 25 de diciembre de 1908: en esta ocasión, un grupo de escritores se da cita en una majestuosa casa, propiedad de Ignacio Reyes, donde tiene lugar una celebración altamente significativa para la historia cultural mexicana. El grupo de invitados es reducido, homogéneo, ninguno de ellos supera los treinta años de edad, todos se conocen entre sí y cuentan ya con un cierto renombre dentro del ambiente cultural de la ciudad de México. Estaban presentes esa noche: el anfitrión y su sobrino, Alfonso Reyes, Pedro Henríquez Ureña, Antonio Caso, Rubén Valenti y se estima que pudieron haber asistido también Julio Torri, Jesús T. Acevedo y Ricardo Gómez Robelo¹.

El encuentro no consistió en una tertulia o reunión de lectura como las que eran habituales entre este grupo de jóvenes, y esto no sólo se debe a la elección de la fecha -teniendo en cuenta que se dieron cita el mismo día de la celebración de la Navidad-, sino porque en ella se llevó a cabo la lectura, por parte de Pedro Henríquez Ureña, de un pequeño drama de su autoría o "ensayo de tragedia griega" como él prefirió llamarlo, por medio del cual anuncia y celebra el nacimiento de Dioniso. A la manera de un ritual de iniciación, imitando las formas y el lenguaje de los poetas trágicos, su autor da lectura a este texto que anuncia el advenimiento de Dioniso y el deseo de la ciudad -expresado a través del coro- de que se convierta en su dios tutelar. La trama si bien se toma algunas licencias, no se aparta demasiado

\footnotetext{
${ }^{1}$ Datos brindados por Quintanilla 2002: 619-620.
} 
de las versiones más conocidas del mito (es sorprendente su escritura porque por momentos creemos estar ante una auténtica tragedia griega si no fuera porque su prosa adopta las modulaciones propias del siglo XIX); su escritura es un "ejemplo antiguo" y Pedro Henríquez Ureña se muestra con este trabajo como un verdadero guardián del gusto por la antigüedad.

Dioniso es presentado en el texto como aquel que nace dos veces, como el que llega siendo un "dios niño, vestido de blanco y oro, a anunciarnos su poder", introduciendo el "entusiasmo de su culto"; ante cuya aparición el coro exclama: " ¡Llega, dios niño, dios virginal, coronado de yedra, coronado de pámpanos, coronado de serpientes; Dioniso fructuoso, lleno de aromas, portador de mieles, amigo de Deméter, maestro de las Gracias; Bromio deleitable, Evio inspirador, Baco benévolo, Leneo resonante, Zagreo rugiente, libertador de corazones, libertador de espíritus! Inspíranos para que dignamente celebremos tus ritos; inícianos en tus misterios sagrados; aquí tendrás tu templo, cabe las fuentes gratas"2. Es con esta evocación, en esta fiesta, en la tertulia, en la noche de Navidad, en que se homenajea al dios de la vid, de la metamorfosis, de la máscara, cuando estos jóvenes "atenienses" (la mayoría de ellos fundarán e integrarán meses después el Ateneo de la Juventud) organizan y asisten a una suerte de ritual profano que se propone consagrar el renacimiento de la vida, el arte y la literatura.

Si este pequeño drama transcurre en la Tebas de Cadmo y Harmonía, si a través de él se prepara a la ciudad para recibir la presencia embriagante y entusiasta del dionisismo, su representación tiene lugar en el México de principios de siglo XX y en una fecha clave -1908- por encontrarse enmarcada en una serie de acontecimientos históricos literarios que otorgan a este texto y a su presentación/representación, un valor simbólico relevante para la formación de la cultura de ese país. Nos referimos a la importancia que el helenismo cultural va a ir adquiriendo en el contexto mexicano de principios de siglo y fundamentalmente de la mano del dominicano Pedro Henríquez Ureña y con una alta repercusión en su discípulo y amigo, Alfonso Reyes. En estas primeras décadas del siglo XX, el dominicano Pedro Henríquez Ureña y el mexicano Alfonso Reyes, a la par que se declaran los "últimos herederos del modernismo" -junto a un grupo de escritores congregados en torno a la Revista Savia Moderna (1906)-, dan testimonio del restablecimiento de la "cultura de las humanidades", a través de sus conferencias-ensayos didácticos, vinculados a un "magisterio" que intenta transmitir la relación existente entre el "arte-poética” y el "arte de la enseñanza" y que buscan proyectar en la juventud de América. Este tipo de discursos encuentra un importante antecedente en la Argentina con las conferencias dictadas en la Universidad de la Plata o de Tucumán por Leopoldo Lugones, quien no es el único autor argentino que demuestra la importancia

\footnotetext{
${ }^{2}$ Henríquez Ureña 2000: 14.
} 
que la cultura clásica tuvo en los tiempos de la reorganización nacional ya que tanto Cané, con su discurso sobre "La enseñanza clásica", pronunciado en 1901 en la Facultad de Filosofía y Letras, como Ricardo Rojas, con su disertación sobre la "Valoración Social de las Humanidades", dictado en 1932 y en la misma Facultad; los anticipan y los secundan.

En el contexto mexicano, entonces, el primer paso vendrá de la mano de la fundación, en 1907, de la Sociedad de Conferencias donde se realizaban lecturas comentadas de los textos griegos. Estas conferencias fueron organizadas -según declara Pedro H. Ureña en sus Memorias (escritas a partir de junio de $1909)^{3}$ - porque sus amigos ya eran asiduos lectores de los griegos y, si bien él fue el impulsor de este programa de lecturas, efectivamente su helenismo encontró un ambiente propicio y estimulante para el ejercicio de su magisterio. El texto del pequeño drama leído por su autor $-y$ que se vuelve el centro de la ceremonia celebrada en honor de Dioniso esa noche mexicana de 1908- indica que este gesto y su elección no pudieron ser ajenos a la influencia de obras como El nacimiento de la tragedia de Nietzsche o los estudios de Walter Pater que él mismo tradujo y publicó en la Revista Moderna y de otros escritos dedicados a la mitología griega y al culto griego a los dioses a que se aplicaron los hombres del siglo XIX y que fueron leídos y estudiados por Pedro Henríquez Ureña, tal como él mismo manifiesta en sus memorias cuando afirma:

En 1907 (un año antes de la escritura del texto que nos ocupa) tomaron nuevos rumbos mis gustos intelectuales. La literatura moderna era la que yo prefería; la antigua la leía por deber, y rara vez llegué a saborearla. Pero, por la época de las conferencias, mi padre había ido a Europa, como delegado de Santo Domingo a la conferencia de La Haya; y le pedí me enviara una colección de obras clásicas fundamentales y algunas de crítica: los poemas homéricos, los hesiódicos, Esquilo, Sófocles, Eurípides, los poetas bucólicos, en las traducciones de Leconte de Lisle, Platón en francés, la Historia de la literatura griega de Otfried Müller, los estudios de Walter Pater (en inglés), los Pensadores griegos de Gomperz, la Historia de la filosofía europea de Alfred Weber, entre otras. La lectura de Platón y del libro de Walter Pater sobre la filosofía platónica me convirtieron definitivamente al helenismo ${ }^{4}$.

Además, vale señalar que en 1908, Pedro Henríquez Ureña y Alfonso Reyes preparan y publican la edición mexicana del Ariel de Rodó (su sermón laico, como atinadamente lo llamó Carlos Real de Azúa, por la influencia romántica del profetismo intelectual), quien diera a través de este libro, la primera "clase magistral" a la juventud de América, tomando como base el legado helénico. Para 1909 se consolida la formación de la empresa ateneísta, con la constitución

\footnotetext{
${ }^{3}$ Cf. Henríquez Ureña 2000: 122-124.

${ }^{4}$ Henríquez Ureña 2000: 122-123.
} 
del Ateneo de la Juventud, el que pasará a convertirse -luego del Centenario y tras el término del porfiriato- en Universidad Popular.

La formación de los Ateneos, tanto en Buenos Aires como en México, cumplió no sólo una función de consagración entre los escritores de la época-conformando un importante centro de legitimación entre sus miembros, de autoconsagración recíproca- sino que además llegaron a convertirse en centros de formación y de difusión de las nuevas propuestas estéticas. La ideología dominante en el campo cultural por los años de la creación del Ateneo mexicano es el positivismo -introducido en México de la mano de Barreda en 1867-, a través del cual los programas educativos se centran cada vez con mayor insistencia en el estudio de las ciencias. Frente al panorama político y social reinante, el que se ve agravado por la inflexible concepción social del porfiriato, las nuevas generaciones de finales del siglo XIX y principios del siglo XX se inclinan por la defensa de las humanidades y toman como modelo la tradición clásica y los numerosos estudios sobre el tema publicados en Europa por esos años (Nietzsche, Wilamowitz, Walter Pater, Livingston, Bérard por nombrar solo algunos). Además, el Modernismo brinda su inconfundible sello cosmopolita, basado en el intercambio entre las literaturas provenientes de diferentes épocas y culturas, y provocando importantes afinidades estéticas entre los escritores ateneístas, la mayoría de los cuales colaboran con uno de los órganos más representativos de este movimiento en México: la Revista Moderna (en la que aparecerá publicada la versión leída por Pedro Henríquez Ureña en el banquete navideño/dionisíaco, unas semanas después; así como también su traducción de los Estudios griegos del ensayista inglés Walter Pater).

La forma trágica griega será la elegida para los primeros escritos literarios de Pedro Henríquez Ureña y de Alfonso Reyes; este último se ha destacado especialmente con la publicación en 1923 de su famoso poema dramático Ifigenia Cruel; pero no debemos olvidar que a la escritura de Ifigenia, lo precede el ensayo que Alfonso Reyes dedica a "Las tres Electras del teatro ateniense" , escrito entre 1908 y 1910 a pedido de su maestro -Pedro Henríquez Ureña y dedicada a él- como un ensayo de ideas griegas (al modo en el que él ensaya la escritura del pequeño drama), y en las que el joven mexicano expone con rigurosidad sus lecturas críticas y exhibe un sutil estilo parnasiano en su prosa. La elección del género trágico en el contexto mexicano tiene lugar complementariamente a la de lírica en Darío y a la épica desplegada por Leopoldo Lugones en Buenos Aires entre finales del siglo XIX y principios del XX, y ponen en evidencia la persistencia de los modelos clásicos en América Latina.

Tragedia, lírica, épica, cosmópolis, cosmopolitismo y esa relación inseparable que existe entre polis y política en las metrópolis hispanoamericanas en el cruce de los siglos, el nacimiento de Dioniso en México, dan cuenta del modo en que la cultura helénica formó parte de los programas culturales, ideológicos y políticos de la intelectualidad latinoamericana, obteniendo un lugar destacado como fuente en un doble sentido convergente: por un lado, Grecia se propone como 
el modelo a seguir en el diseño de las ciudades-estado en formación, otorgando las bases espirituales y morales exigidas para el reordenamiento social de las flamantes Atenas hispánicas. Por el otro, Grecia será fuente del idealismo en el pensamiento y el arte y de allí provendrá su vitalismo y la fuerza inextinguible de su paideia. En esta doble vertiente, volver a Grecia posibilitará una propedéutica para que desde el coloquio y la cátedra se tracen los lineamientos básicos de los proyectos culturales y para que la elaboración de los programas de un nuevo orden social encuentren su formulación utópica e intenten proyectar sus efectos educativos y políticos.

Pedro Henríquez Ureña fue ante todo un maestro. Y su pregunta por la tradición, su lectura de los clásicos, su propuesta de retorno a la cultura de las humanidades encierra o contiene una pregunta sobre la función social de la literatura. Sobriedad y embriaguez caracterizan a este maestro de las letras hispanoamericanas que ha recibido el apodo de Sócrates por sus contemporáneos, por su paideia, por el heroísmo cultural ${ }^{5}$ con que ha sostenido su utopía de América. Pedro Henríquez Ureña es representativo de un ideario de época y con este ensayo de tragedia, el dominicano comienza a desplegar una intensa tarea de reflexión destinada a dar cuenta de su programa cultural; y vuelve a Grecia, porque Grecia (y cito un fragmento de la conferencia que diera en ocasión de la reapertura de las clases en la Escuela de Altos de Estudios de México en 1914):

... no es solo mantenedora de la inquietud del espíritu, del ansia de perfección, maestra de la discusión y de la utopía, sino también ejemplo de toda disciplina. De su aptitud crítica nace el dominio del método, de la técnica científica y filosófica; pero otra virtud más alta todavía la erige en modelo de disciplina moral. El griego [...] creyó en la perfección del hombre como ideal humano, por humano esfuerzo asequible, y preconizó como conducta encaminada al perfeccionamiento, como prefiguración de la perfecta, la que es dirigida por la templanza, guiada por la razón y el amor. El griego no negó la importancia de la intuición mística, del delirio -recordad a Sócrates- pero a sus ojos la vida superior no debía ser el perpetuo éxtasis o la locura profética, sino que habría de alcanzarse por la sofrosine. Dionisos inspiraría verdades supremas en ocasiones, pero Apolo debía gobernar los actos cotidianos ${ }^{6}$.

-afirma convencido de la que la educación -entendida en el amplio sentido humano que le atribuyeron los griegos- es la única salvadora de los pueblos.

\footnotetext{
5 Weinberg, Liliana (2010), "Pedro Henríquez Ureña; hacer legible la revolución”, in Martínez Carrizales, Leonardo coord. 2010: 51-107.

${ }^{6}$ Henríquez Ureña 2000b: 18.
} 


\section{BibLIOgRAFía genERAL}

García Morales, A. (1992), El Ateneo de México 1906-1914. Orígenes de la cultura mexicana contemporánea. Sevilla: Publicaciones de la Escuela de Estudios Hispano-americanos de Sevilla.

Henríquez Ureña, P. (1982), La utopía de América. Caracas: Ed. Ayacucho.

Henríquez Ureña, P. (2000a), Memorias. Diario. Notas de Viaje. México: Ed. Del Fondo de Cultura Económica.

Henríquez Ureña, P. (2000b), "El nacimiento de Dionisos" y "La cultura de las humanidades", in Abellán, J. L., Barrenechea, A. M. (eds.), Ensayos. Buenos Aires, Editorial Sudamericana: 5-17; 18-28.

Martínez, J. L. (ed.) (1986), "Introducción 1907-1914", in Correspondencia I (correspondencia entre Pedro Henríquez Ureña y Alfonso Reyes). México, Fondo de Cultura Económica: 9-39.

Martínez Carrizales, L. (ed.) (2010), El orden cultural de la Revolución Mexicana. Sujetos, representaciones, discursos y universos conceptuales. México: Universidad Autónoma Metropolitana.

Quintanilla, S. (2002), "Dioniso en México o como leyeron nuestros clásicos a los clásicos griegos”, in Historia mexicana 51 (3): 619-663.

Quintanilla, S. (2008), "Nosotros. La juventud del Ateneo de México”. México: Ed. Tusquets. 